ISSN: 1858 - 6007

$$
\text { مجلة العلوم و التقانة ـ جامعة أم درمان الإسلامية ـ وزارة التعليم العالي و البحث العلمي ـ السودان }
$$

\title{
Long-range proton-carbon coupling constants for the determination of the stereochemical structure of organic compounds.
}

\author{
Anwar, E. M. Noreljaleel \\ anwarelbushra@yahoo.ca \\ Department of Chemistry, Omdorman Islamic University, Faculty of Science \\ and Technology, Khartoum, Sudan

\begin{abstract}
A new methods for elucidating stereochemistry of organic compounds was developed on the basis of long-range proton-carbon coupling constants $\left({ }^{2,3} J_{\mathrm{C}, \mathrm{H}}\right)$ and interpreting spincoupling constants $\left({ }^{3} J_{\mathrm{H}, \mathrm{H}}\right)$. Reaction of compound containing pyrin ring with nucleophile reagent was done to open the ring. HSQC-TOCSY experiments one of the new NMR spectroscopy method used to measure this values of spin-coupling constants and elucidating the stereochemistry of the product.
\end{abstract}

\section{Introduction}

Nuclear magnetic resonance (NMR) spectroscopy is one of the most important instrumental analysis methods for organic compounds. Some new nuclear magnetic resonance (NMR)

Keywords: HSQC-TOCSY, J-coupling, 2D NMR

\section{Introduction:}

Approaches used to elucidate chemical structures, which have not been determined by routine NMR methods (Nolis and Parella, 2005). In acyclic systems, the conformation of adjacent asymmetric centers is represented by staggered rotamers, and their relative stereochemistry can be determined using ${ }^{2,3} \mathrm{~J}_{\mathrm{C}, \mathrm{H}}$ and ${ }^{3} \mathrm{~J}_{\mathrm{H}, \mathrm{H}}$, because the combined use of 
these $\mathbf{J}$ values enables the identification of the predominant staggered rotamer(s) out of the six possible derived from threo and erythro configurations (table 1).

Table 1: J values of staggered rotamer(s)

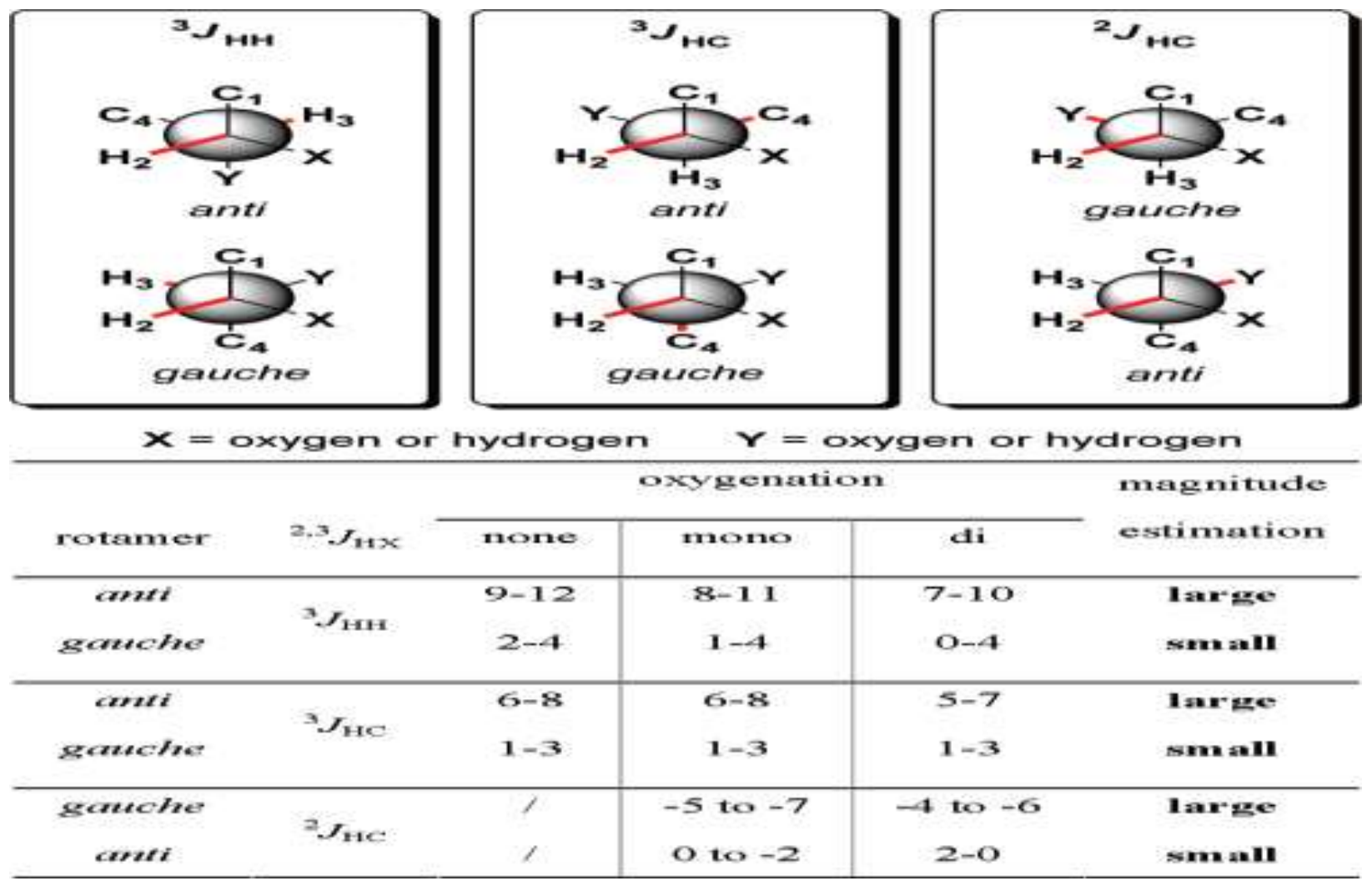

The structural elucidation of highly hydrogen-deficient molecules might be a problem because the carbon network of such molecules cannot be completely followed by heteronuclear long-range $\mathrm{C}-\mathrm{H}$ correlation spectroscopy, such as $\mathrm{HMBC}$ which usually detect the long-range $\mathrm{J}$ coupling between a proton and carbon connected via three or less bonds (Parella and Espinosa, 2013). When the 1H-NMR signals of a compound overlap, it is difficult to analyze them by such homonuclear $1 \mathrm{H}-1 \mathrm{H}$ correlation methods as COSY,TOCSY, NOESY, and ROESY. In this case, it is effective to use 13C information by such heteronuclear 2D NMR methods as HMQC (or HSQC)-TOCSY and HMQC (or HSQC)-NOESY(or ROESY). While HMQC-TOCSY and HSQC-TOCSY are widely used, there is only limited application of HMQC (or HSQC)-NOESY (or ROESY) to organic compounds because of their low sensitivity. NOESY and ROESY experiments are much less sensitive than TOCSY (Goffin et al., 1999).

Table 2: Heteronuclear 2D NMR methods 


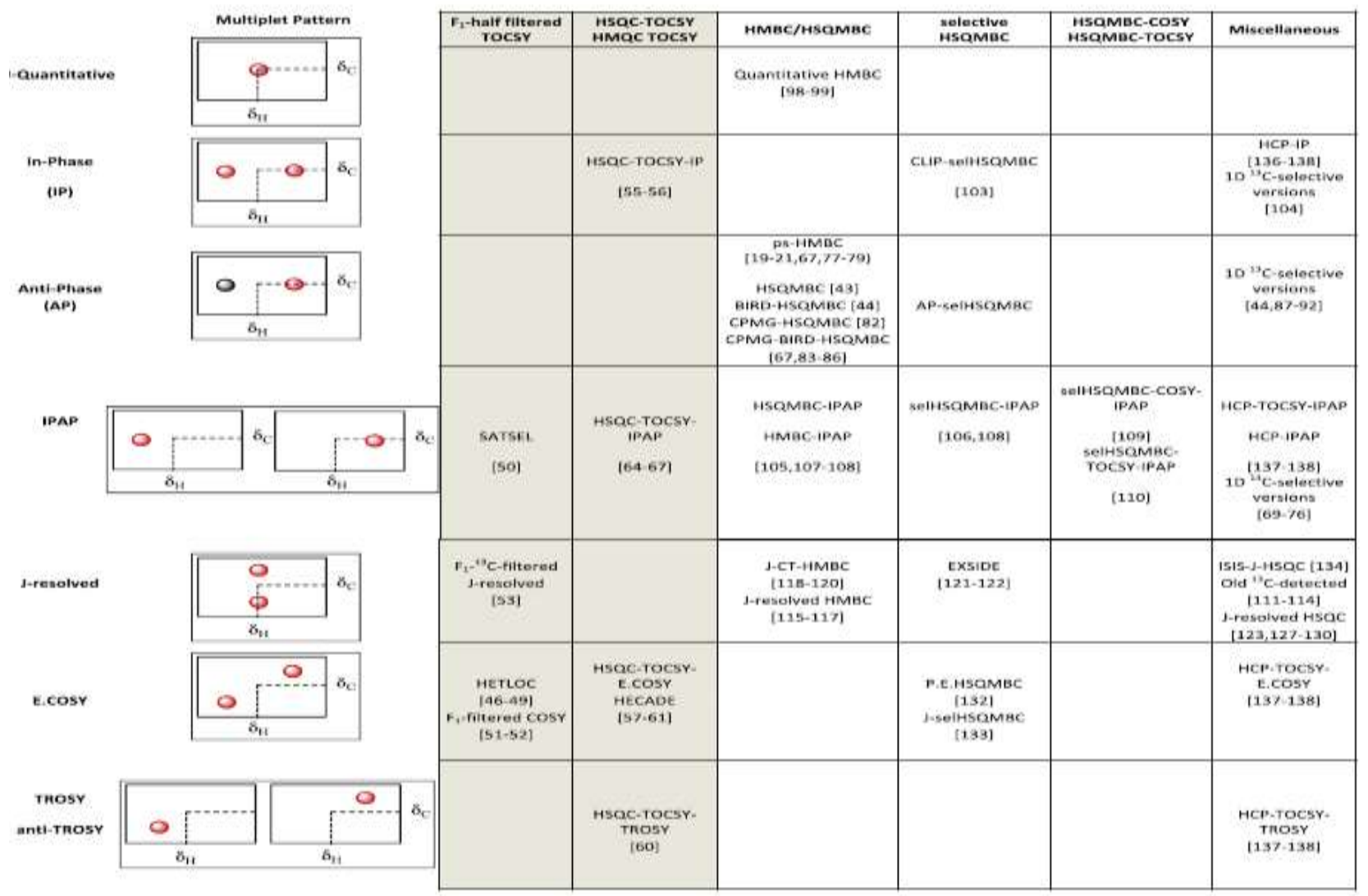

The peaks spelling in 2D spectra a cross the diagonal which indicated by arrow in figure 1 provide the configuration will be anti if the value of ${ }^{2} \mathbf{J}$ CxHa is positive and the configuration will be in gauche form if the ${ }^{2} \mathrm{~J}_{\mathrm{CxHa}}$ is negative (Ludwig and Viant, 2010).
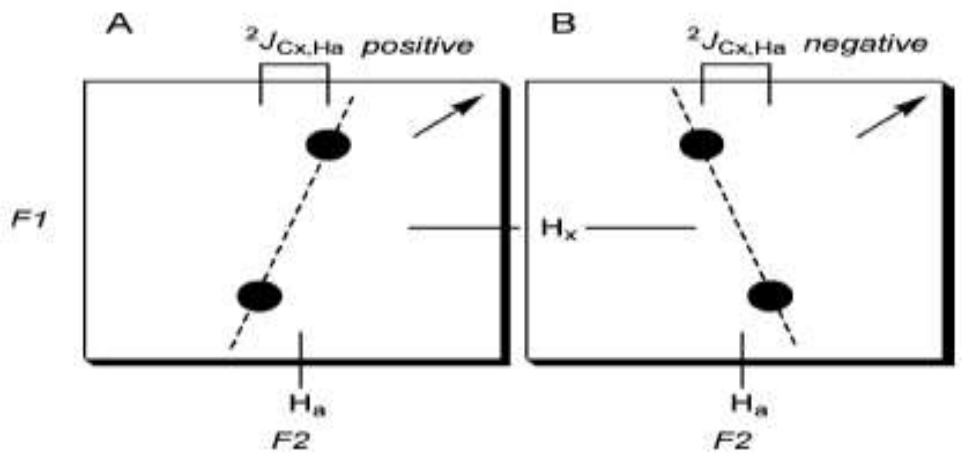

Fig 1: positive and negative value of $\mathrm{J}$ coupling constant from $2 \mathrm{D}$ NMR.

The direct measurement of ${ }^{2,3} \mathrm{~J}_{\mathrm{HC}}$ coupling constants achieved by measuring the distance between the splitting peak through the $\mathrm{X}$ axis (the proton spectra), while the distance on $\mathrm{Y}$ axis (carbon spectra represented the ${ }^{1} \mathrm{~J}_{\mathrm{CH}}$ value (Matsumori, et al., 1999). 


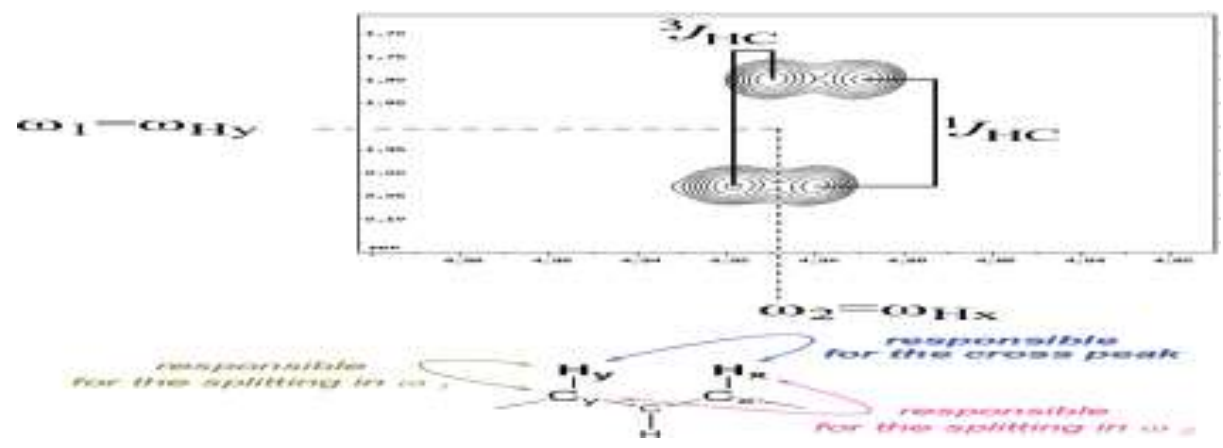

Fig 2: Direct measuring of ${ }^{2,3} \mathrm{JHC}_{\mathrm{HC}}$ coupling constants from $2 \mathrm{D}$ NMR.

\section{Experimental}

The compound containing pyrin ring was refluxed overnight with sodium sulfite as nucleophile in water the ring was opened. After removing water, the sulfite salt precipitated by methanol. The product was analyzed by NMR spectroscopy using HSQC-TOCSY experiments.

\section{Discussion}

The reaction of compound containing pyrin ring with nucleophile produced opening ring product and according to reaction mechanism the nucleophile attached into an anti position of hydroxyl group. Firstly, HSQC experiments were used to identified each proton attached with which carbon of the product (figure 3). Secondly HSQC-TOCSY experiments (figure 4) was used to measure the values of carbon-proton spin-coupling constants $\left({ }^{2,3} J_{\mathrm{C}, \mathrm{H}}\right)$. According to the big negative value of the ${ }^{2} J_{\mathrm{C}, \mathrm{H}}$ which equal -6 to $-8 \mathrm{~Hz}$ and small negative value of the ${ }^{3} J_{\mathrm{C}, \mathrm{H}}$ which equal -2 to $-3 \mathrm{~Hz}$, the stereochemistry of the product look like conformer i illustrated in the scheme 1 below.

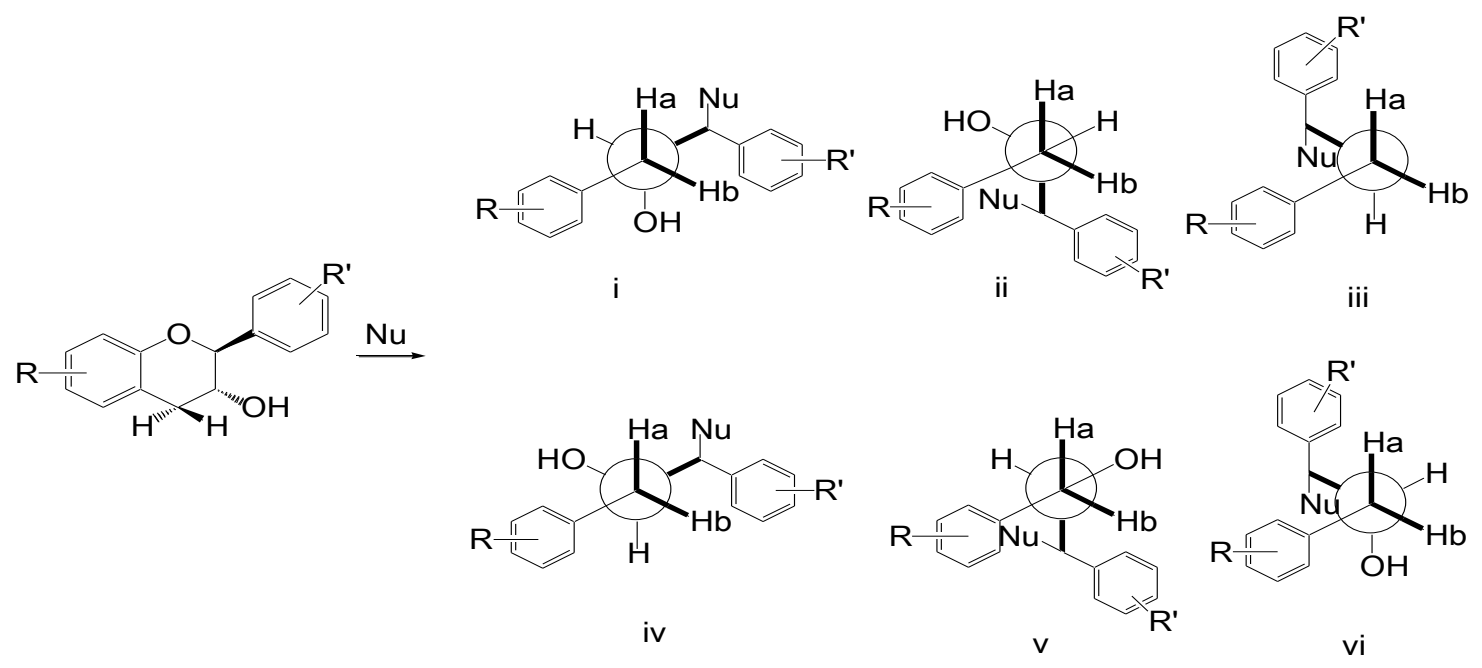


Scheme 1: The six possibility of the conformer of ring opening product.

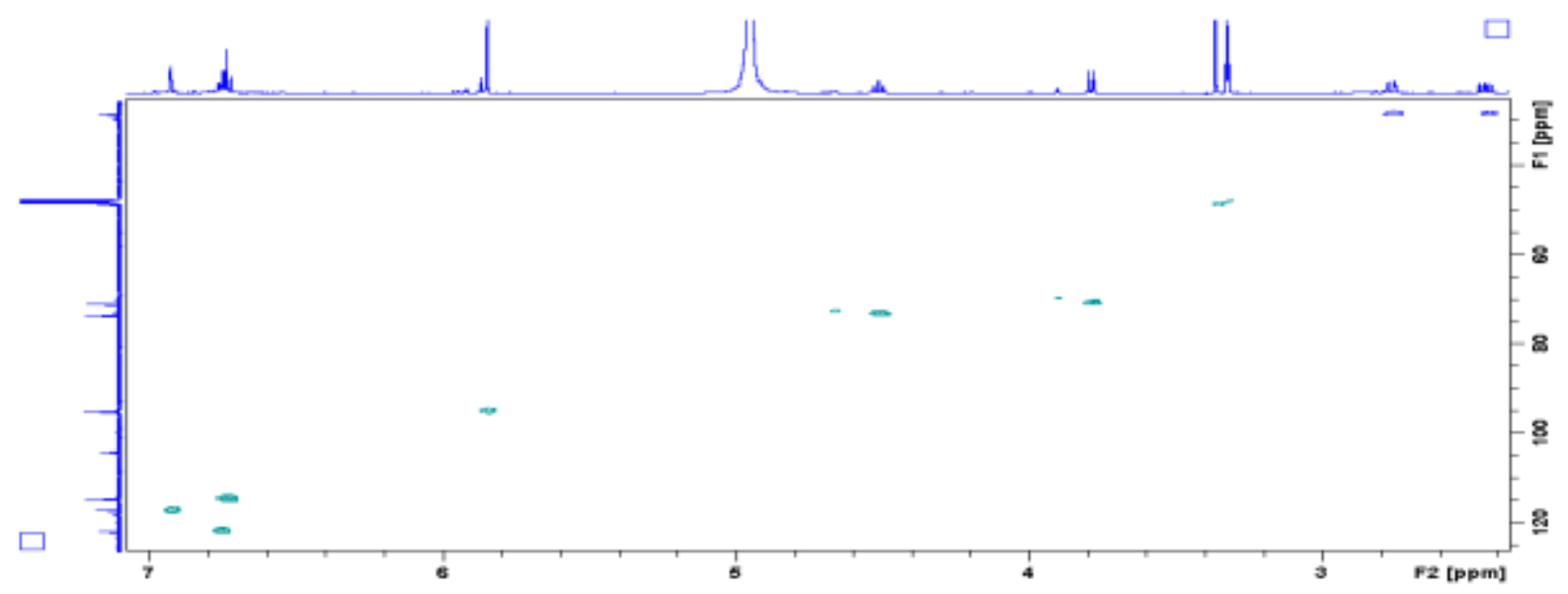

Fig 3: Fig 4: HSQC experiments of the product

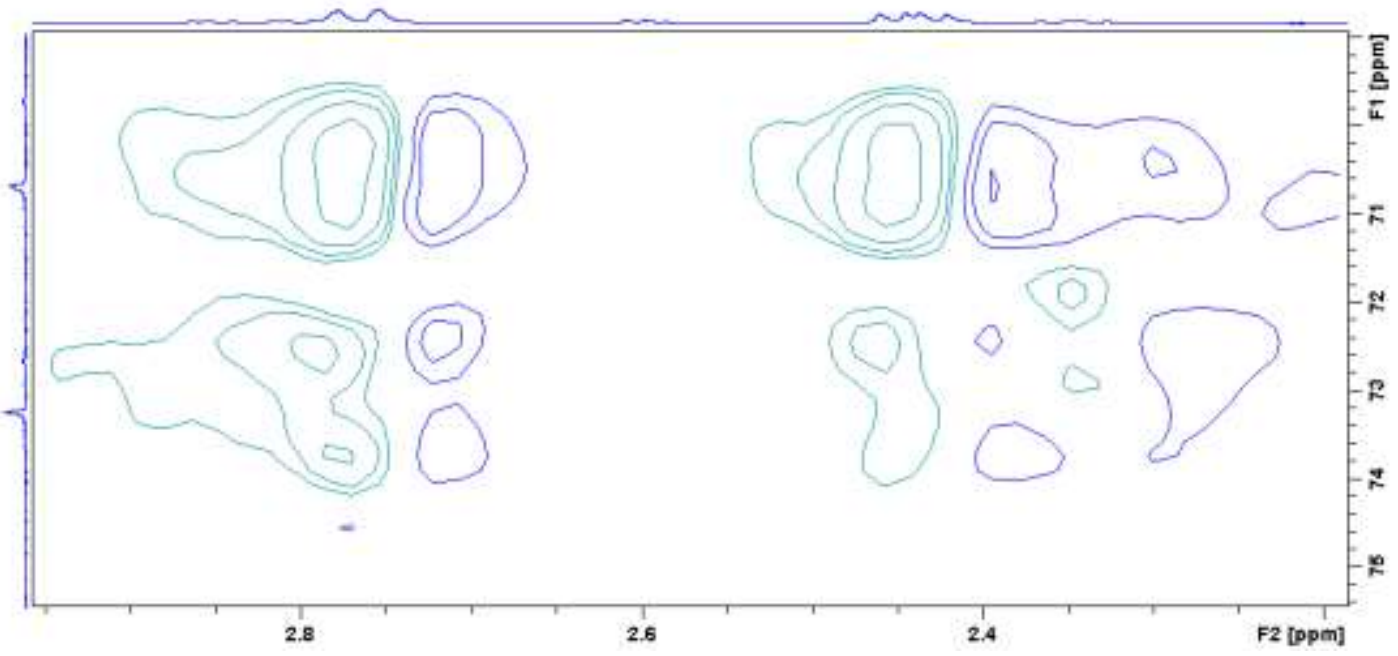

Fig 4: HSQC-TOCSY experiments of the product

Also in ${ }^{1} \mathrm{HNMR}$ spectra of the product (figure 5) observed that the ${ }^{3} J_{\mathrm{H}, \mathrm{H}}$ coupling of the proton which located neighboring to the tow protons $(\mathrm{Ha}$ and $\mathrm{Hb}$ ) of the methelene group in the conformer I it site in gauche position with proton $\mathrm{Ha}$ (small $\mathrm{j}$ value between $1-3$ ) and site at anti postion $\mathrm{Hb}$ (big $\mathrm{j}$ value 9.3 and $14.4 \mathrm{~Hz}$ ). In the conformer iv this proton site in gauche position with proton $\mathrm{Hb}$ and at anti postion $\mathrm{Ha}$. This observation improve the result coming from the values carbon-proton spin-coupling constants $\left({ }^{2,3} J_{\mathrm{C}, \mathrm{H}}\right)$ which indicated that the conformer of the product like conformer number $i$ in the scheme 1. 


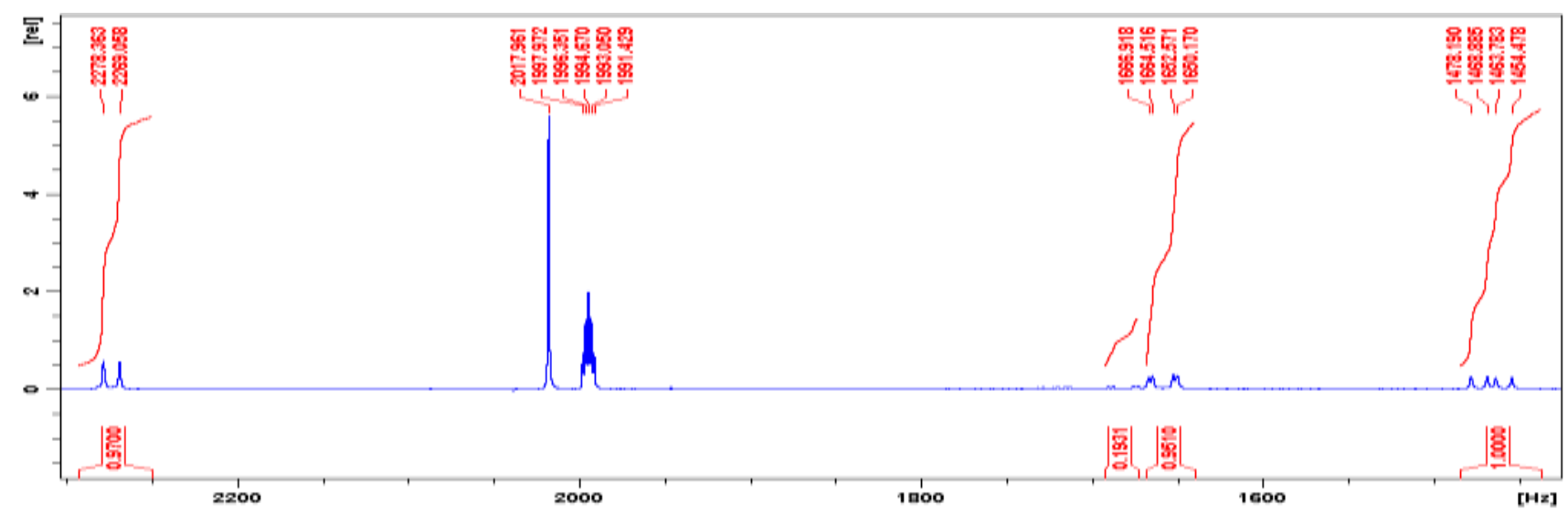

Fig 5: ${ }^{1}$ HNMR spectra of the product

\section{Conclusions:}

The J-coupling constants contain very useful information especially when it used to identifying the molecular conformation. The 2D NMR HSQC-TOCSY experiments is a useful method to measured J-coupling constants which can be used to elucidating the stereochemistry of organic compounds.

\section{References}

Goffin, D.; Bystricky, P., Shashkov, A. S., Lynch, M., Hanon, E., Paquot, M. and Savage, A. V.; (2009); A Systematic NMR Determination of $\alpha$-D-Glucooligosaccharides, Effect of Linkage Type, Anomeric Configuration and Combination of Different Linkages Type on 13C Chemical Shifts for the Determination of Unknown Isomaltooligosaccharides; Bull. Korean Chem. Soc. Vol. 30, No. 112535

Ludwig, C and Viant, M. R.; (2010); Two-dimensional $J$-resolved NMR Spectroscopy: Review of a Key Methodology in the Metabolomics Toolbox; Phytochem. Anal.; 21; 2232.

Matsumori, N., Kaneno, D., Murata, M., Nakamura, H. and Tachibana, K.; (1999); Stereochemical Determination of Acyclic Structures Based on Carbon-Proton SpinCoupling Constants. A Method of Configuration Analysis for Natural Products.; J. Org. Chem.; 64, 866-876 
Nolis, P. and Parella, T.; (2005); Spin-edited 2D HSQC-TOCSY experiments for the measurement of homonuclear and heteronuclear coupling constants: Application to carbohydrates and peptides; Journal of Magnetic Resonance 176 15-26

Parella, T. and Espinosa, J. F.; (2013) ; Long-range proton-carbon coupling constants: NMR methods and applications; Progress in Nuclear Magnetic Resonance Spectroscopy; $73 ; 17-55$ 